\title{
Effects of soil nutrients on the sequestration of plant defence chemicals by the specialist insect herbivore, Danaus plexippus
}

\author{
L E I L I N G $\mathrm{TA} \mathrm{O}^{\dagger}$ and M A R K D. H U N T E R Department of Ecology and Evolutionary Biology, \\ University of Michigan, Ann Arbor, Michigan, U.S.A.
}

\begin{abstract}
Although anthropogenic nitrogen (N) enrichment has significantly changed the growth, survival and reproduction of herbivorous insects, its effects on the defensive sequestration of secondary chemicals by insect herbivores are less well understood. Previous studies have shown that soil nutrient availability can affect sequestration directly through changing concentrations of plant defence chemicals, or indirectly through altering growth rates of herbivores. There has been less exploration of how nutrient deposition affects the consumption of secondary chemicals and subsequent sequestration efficiency. In the current study, the overall effect of soil $\mathrm{N}$ availability on cardenolide sequestration by the monarch caterpillar Danaus plexippus was examined. Specifically, the effects of soil nutrient availability on growth, consumption, excretion and sequestration efficiency of cardenolides by D. plexippus larvae fed on the tropical milkweed Asclepias curassavica were measured.

2. The results showed that soil $\mathrm{N}$ and phosphorus (P) fertilisation significantly reduced caterpillar growth rate and the sequestration efficiency of cardenolides by monarch caterpillars feeding on A. curassavica. The lowered sequestration efficiency was accompanied by higher concentrations of cardenolides in frass. Although the total cardenolide contents of caterpillars were lower under high $\mathrm{N}$ or $\mathrm{P}$ fertilisation levels, caterpillar cardenolide concentrations were constant across fertilisation treatments because of lower growth rates (and therefore lower body mass) under high fertilisation. It is concluded that anthropogenic $\mathrm{N}$ deposition may have multiple effects on insect herbivores, including their ability to defend themselves from predators with sequestered plant defences.
\end{abstract}

Key words. Asclepias curassavica, cardenolide, Danaus plexippus, nitrogen deposition, phosphorus, plant secondary metabolites, sequestration.

\section{Introduction}

Anthropogenic nitrogen $(\mathrm{N})$ deposition has significantly altered community structure and ecosystem functioning, as well as species interactions within communities (Vitousek et al., 1997; Galloway et al., 2004). For example, interactions between insect herbivores and their host plants may change under $\mathrm{N}$ deposition because herbivores can be strongly N-limited (Mattson, 1980; Elser et al., 2000; Awmack \& Leather, 2002). However, the effects of $\mathrm{N}$ deposition on herbivore performance are

Correspondence: Leiling Tao, Department of Ecology and Evolutionary Biology, University of Michigan, 2082 Natural Science Building, Ann Arbor, MI 48109, U.S.A. E-mail: 1tao@emory.edu

${ }^{\dagger}$ Current address: Biology Department, Emory University, 1174 O. Wayne Rollings, 1510 Clifton Road, Atlanta, GA 30322, U.S.A. much more complicated than simple relaxation of $\mathrm{N}$ limitation (Throop \& Lerdau, 2004). For example, $\mathrm{N}$ deposition can change the concentrations of plant secondary metabolites (PSMs) (Tao \& Hunter, 2012) and plant species composition (Bobbink et al., 2010), both of which can significantly alter insect population growth rates and community structure. Moreover, $\mathrm{N}$ deposition may influence herbivore-enemy interactions, although such effects have received much less attention (Throop \& Lerdau, 2004). For many specialist insect herbivores, defence against natural enemies includes the sequestration of PSMs from their host plants (Nishida, 2002; Opitz \& Müller, 2009). Therefore, for a more complete understanding of the ecological effects of $\mathrm{N}$ deposition, it is important to consider the effects of $\mathrm{N}$ deposition on the sequestration of PSMs by herbivores (Prudic et al., 2005; Jamieson \& Bowers, 2012). 
The amount of PSMs sequestered by insects is determined simultaneously by the consumption of the chemical and its sequestration efficiency (i.e. the ability to incorporate dietary chemicals into the body), both of which can be affected by soil $\mathrm{N}$ availability. When foliar $\mathrm{N}$ concentrations are low, insect herbivores may increase their total food intake to compensate for inadequate nutrient uptake (Docherty et al., 1996). Therefore, $\mathrm{N}$ deposition may reduce total consumption of leaf tissues by insect herbivores. However, foliar consumption levels are also determined by concentrations of PSMs in plant tissues (Bernays \& Chapman, 1987), which in turn can be affected by soil $\mathrm{N}$ availability (Jamieson \& Bowers, 2012). As a result, the overall effects of $\mathrm{N}$ deposition on total consumption of PSMs depend upon the magnitude and direction of changes in foliar $\mathrm{N}$ and PSM concentrations, as well as specific responses of insects to these two variables.

Potential effects of $\mathrm{N}$ deposition on sequestration efficiency are much more complex. Sequestration efficiency describes the proportion of ingested defence chemical that is retained by the herbivore (Bowers \& Collinge, 1992; Camara, 1997), which reflects the ability of the insect to actively and selectively absorb, transform and store PSMs. Sequestration efficiency appears to be tightly regulated by herbivores according to their ontogeny (Bowers \& Collinge, 1992), host plant chemical composition (Burghardt et al., 2001; Bowers, 2003), insect genotype (Camara 1997) and sex (Burghardt et al., 2001). In addition, sequestration efficiency reflects the ability of insect herbivores to avoid autotoxicity and eliminate excess PSMs, which should be actively selected for during the evolution of sequestration (Camara 1997). Therefore, sequestration efficiency is co-determined by resource allocation to sequestration, chemical composition of the diet, and toxicity of the sequestered chemicals, all of which can be affected by $\mathrm{N}$ deposition (Keinänen et al., 1999; Tao et al., 2014). Thus far, however, the overall effects of $\mathrm{N}$ deposition on sequestration efficiency remain unclear.

In the current study, we explored the effects of $\mathrm{N}$ deposition on the sequestration of cardenolides from the tropical milkweed, Asclepias curassavica by the monarch caterpillar, Danaus plexippus. Monarchs are well known for their ability to use cardenolides sequestered from their Asclepias hosts as a defence against predators (Reichstein et al., 1968), but the ecological factors determining the extent and efficiency of sequestration are less clear. Previously, we reported that $\mathrm{N}$ deposition can have positive (Tao \& Hunter, 2012), neutral or even negative (Tao et al., 2014) effects on the growth rate of D. plexippus, depending on host plant species. Specifically, for monarch caterpillars feeding on A. curassavica, increases in foliar $\mathrm{N}$ concentration lead to higher cardenolide toxicity, resulting in overall deleterious effects of $\mathrm{N}$ deposition on caterpillar performance (Tao et al., 2014). Based on this result, we predicted here that monarch larvae feeding on A. curassavica would exhibit a lower sequestration efficiency of cardenolides under high $\mathrm{N}$ deposition. Our prediction could be realised through two alternative mechanisms: (i) when growth rate and overall insect vigour are low, allocation to defence functions may also be low (Bukovinszky et al., 2009); or (ii) in order to reduce the toxicity of cardenolides under high-N conditions, D. plexippus may increase food passage rate, leading to lower sequestration efficiency.

To test our prediction and the potential mechanisms underlying it, we examined the effects of soil nutrient availability on growth, consumption, excretion and sequestration efficiency of cardenolides by $D$. plexippus fed on A. curassavica. We incorporated both soil $\mathrm{N}$ and phosphorus (P) in our treatments, as $\mathrm{N}$ deposition can change the effects of soil $\mathrm{P}$ on species interactions (Zehnder \& Hunter, 2009; Vitousek et al., 2010). In addition, we explored the effects of soil nutrient availability on foliar cardenolide concentration and composition. Integrating these analyses, we were able to examine the overall effects of soil nutrient availability on cardenolide sequestration by $D$. plexippus.

\section{Materials and methods}

The tropical milkweed, A. curassavica, is native to the American tropics, and serves as a host plant for the monarch caterpillar, D. plexippus. The specialist monarch has evolved substantial resistance to cardenolides (Holzinger \& Wink, 1996) and the ability to sequester them as a defence against predators (Reichstein et al., 1968). However, very high cardenolide concentrations, and some lipophilic cardenolide forms, can reduce monarch performance in the absence of natural enemies (Sternberg et al., 2012). Previous studies have shown that the sequestration of cardenolides by $D$. plexippus is highly selective, such that sequestration efficiency is subject to change with variation in foliar cardenolide concentration and composition (Malcolm et al., 1989).

We purchased A. curassavica seeds from Butterfly Encounters Inc (San Ramon, California). The seeds were germinated on damp filter paper in Petri dishes at $25^{\circ} \mathrm{C}$. After germination, seedlings were planted in 4-inch plant pots containing a 1:1 mixture of potting soil (SunGrow Horticulture, Agawam, Massachusetts) and sand (Kolorscape, Atlanta, Georgia). Plants were kept in a controlled growth chamber at $25^{\circ} \mathrm{C}$ and an LD 16:8 h (Philips F32T8/ADV835/ALTO 32 Watt T8 high lumen fluorescent bulbs). When plants were 3 weeks old, $3 \times 3$ levels of $\mathrm{N}$ and $\mathrm{P}$ fertiliser were applied in a factorial design. $\mathrm{N}$ was added as ammonium nitrate at levels of 0,4 and $8 \mathrm{~g} \mathrm{~m}^{-2}$, and $\mathrm{P}$ was added as calcium phosphate monobasic at levels of $0,0.4$ and $0.8 \mathrm{~g} \mathrm{~m}^{-2}$. Fertiliser was applied once every week for a total of 5 weeks; each plant received one-fifth of its total fertiliser allocation each week. We have shown previously that these levels of fertilisation generate a broad but realistic range of C:N:P stoichiometry in milkweed plants (Tao \& Hunter, 2012) and the $\mathrm{N}$ addition treatments fall within the range of anthropogenic $\mathrm{N}$ deposition levels observed in nature (Fenn et al., 2003). We used 10 plants per treatment, resulting in a total of 90 plants.

We started our experiment 2 days after the last fertilisation, when plants were just over 8 weeks old. Before feeding the leaves to individual caterpillars, we measured foliar cardenolide concentrations from each plant using methods described in Zehnder and Hunter (2009). Briefly, six leaf disks (0.25 inches in diameter) from the fourth pair of leaves of each plant were taken and ground in methanol using a ball mill and sonicated at $60^{\circ} \mathrm{C}$ for $1 \mathrm{~h}$. Although sampling from a single leaf cannot account 
for chemical variation among leaves, within-plant variation in cardenolide chemistry is negligible in A. syriaca (M. D. Hunter, unpublished). Another six leaf disks were taken, weighed for fresh weight and then oven-dried to provide estimates of foliar fresh/dry weight ratios for each plant. The supernatant from samples in methanol was evaporated at $45^{\circ} \mathrm{C}$ for $70 \mathrm{~min}$ until dryness. Samples were then resuspended in $150 \mu$ l of methanol containing $0.15 \mathrm{mg} \mathrm{ml}^{-1}$ digitoxin as an internal standard and analysed using reverse-phase ultra-performance liquid chromatography (UPLC, Waters Inc., Milford, MA, USA). The running time for each sample was 9 min. Peaks were detected by absorption at $218 \mathrm{~nm}$ using a diode array detector, and absorbance spectra were recorded from 200 to $300 \mathrm{~nm}$. Peaks with symmetric absorption maxima between 216 and $222 \mathrm{~nm}$ were recorded as cardenolides (Zehnder \& Hunter, 2007). Total cardenolide concentration was calculated as the sum of all separated cardenolide peaks, corrected by the concentration of the internal standard (digitoxin) and the estimated sample mass. For the same leaves from which disks were taken, the remaining leaf material was oven-dried and ground for subsequent carbon (C), N and P measurements. Foliar $\mathrm{C}$ and $\mathrm{N}$ concentrations were measured on a $\mathrm{CHN}$ analyser (Costech, Valencia, CA, USA) and foliar P concentrations were quantified on an autoanalyser using an acid digestion method (Tao \& Hunter, 2012).

Danaus plexippus eggs were obtained from a colony maintained in our laboratory. We obtained monarchs from two sources: from a commercial butterfly breeder (Shady Oaks Butterfly Farm, Brooker, Florida) and as the offspring of a native Florida population collected during the previous year. We then conducted six random crosses of butterflies from these origins, and assigned their offspring randomly to the treatments. Around 100 eggs were collected for the experiment and stored in a refrigerator for 2 days before the experiment to synchronise hatching of the 90 larvae required for our experiment. Each neonate caterpillar was assigned randomly to receive foliage from a single plant. Caterpillars were maintained individually in $163 \mathrm{ml}$ plastic containers. Each day, we retrieved fresh leaves from each plant and fed them ad libitum to their associated caterpillars. To quantify consumption, we measured the fresh weight of leaves fed to each caterpillar, and converted it to dry weight using the fresh/dry conversion described earlier. Before the next feeding, we retrieved the leftover leaves from the previous day, oven-dried and weighed them. Consumption was then calculated as the difference in dry mass between amounts fed to each caterpillar and leftover leaves. The experiment lasted for 7 days in total, which represents $50 \%$ of the average larval period of monarchs under our rearing conditions: plants were not large enough to rear all caterpillars through to pupation, so we kept the number of rearing days constant to better compare growth rates among treatments. Effects of foliage quality on monarch growth are known to be most important during early instars (Zalucki et al., 2001). After 7 days of feeding, all caterpillars were starved for $24 \mathrm{~h}$ to void their gut contents. They were then oven-dried and their dry mass measured on a microbalance. Each day, frass from each caterpillar was also collected, dried and weighed. Caterpillar and frass cardenolide concentrations were measured by UPLC as described earlier.

\section{Statistical analysis}

Total consumption was calculated as the sum of consumption on each day, and total consumption of cardenolides was calculated as the product of foliar cardenolide concentration and total consumption. The average daily growth rate of each caterpillar was calculated by dividing its log-transformed mass by 7 . Total cardenolide content of each $D$. plexippus individual was calculated as the product of caterpillar mass and cardenolide concentration. Sequestration efficiency was calculated by log-transforming the quotient of total cardenolide content of caterpillars by their total consumption of foliar cardenolide. During the experiment, 20 caterpillars died and were excluded from further analysis of caterpillars.

To explore the effects of our $\mathrm{N}$ and $\mathrm{P}$ fertilisation treatments on foliar chemical traits, we used $\mathrm{N}$ and $\mathrm{P}$ treatment levels and their interactions as independent variables, and foliar N, P and cardenolide concentrations as dependent variables in separate two-way ANOVAs. To examine how fertilisation affected growth rate, total consumption of plant material, consumption, excretion and sequestration efficiency of cardenolides, cardenolide concentration and total cardenolide contents of D. plexippus, we used these measurements as dependent variables, and $\mathrm{N}$, $\mathrm{P}$ fertilisation and their interactions as independent variables in separate two-way ANOvas. In addition to $F$ - and $P$-values, we also reported standard $\eta^{2}$ as measurements of effect sizes. If $\eta^{2}>0.14$, the effect size is considered as large, whereas $\eta^{2}<0.01$ is considered as small (Cohen, 1988). Whenever significant interactions between $\mathrm{N}$ and $\mathrm{P}$ fertilisation were detected, we ran additional one-way ANOVAs for each factor separately.

To test the effects of soil $\mathrm{N}$ and $\mathrm{P}$ concentrations on the composition of cardenolides in A. curassavica and D. plexippus, we performed permutational multivariate analysis of variance (PERMANOVA) with $\mathrm{N}, \mathrm{P}$ and their interactions as independent variables, and Bray-Curtis distance of percentage weight of each cardenolide peak as dependent variables (Anderson, 2001). To visualise cardenolide composition, we used non-metric multidimensional scaling (NMDS) with 999 permutations per model run and a maximum of 20 run per dimension. The stress of two-dimensional models was 0.11 for cardenolides in A. curassavica and $D$. plexippus. PERMANOvA and NMDS scaling were performed using the VEGAN package in $\mathrm{R}$, and all analyses were conducted in the base package of R 2.15.2 (2012).

\section{Results}

\section{Effects of soil nutrient availability on consumption and sequestration efficiency of cardenolides by D. plexippus}

Foliar N, P and cardenolide concentrations were all influenced significantly by the interaction between $\mathrm{N}$ and $\mathrm{P}$ fertilisation levels (results of two-way ANOvas provided in Table 1) and here we present the results of subsequent one-way ANOVA for each factor separately. $\mathrm{N}$ fertilisation significantly increased foliar $\mathrm{N}$ and $\mathrm{P}$ concentrations in $A$. curassavica $\left(F_{2,87}=39.06, P<0.001\right.$; $\left.F_{2,87}=5.76, P=0.004\right)$. Foliar cardenolide concentration also varied with $\mathrm{N}$ fertilisation $\left(\mathrm{F}_{2,84}=11.80, P<0.001\right)$. Specifically, the highest cardenolide concentration $\left(3.59 \pm 0.31 \mathrm{mg} \mathrm{g}^{-1}\right)$ 
Table 1. Effects of nitrogen $(\mathrm{N})$ and phosphorus $(\mathrm{P})$ fertilisation, and their interaction, on foliar $\mathrm{N}, \mathrm{P}$ and cardenolide concentrations of Asclepias curassavica.

\begin{tabular}{|c|c|c|c|c|c|c|c|c|c|}
\hline & \multicolumn{3}{|l|}{ Soil N } & \multicolumn{3}{|l|}{ Soil P } & \multicolumn{3}{|l|}{ Soil $\mathrm{N} \times \mathrm{P}$} \\
\hline & $F$ & $P$ & $\eta^{2}$ & & $P$ & $\eta^{2}$ & $F$ & $P$ & $\eta^{2}$ \\
\hline Foliar N & $F_{2,81}=51.46$ & $<0.001$ & 0.47 & $F_{2,81}=3.00$ & 0.06 & 0.03 & $F_{2,81}=6.90$ & $<0.001$ & 0.13 \\
\hline Foliar P & $F_{2,81}^{2,81}=7.08$ & 0.001 & 0.12 & $F_{2,81}^{2,01}=2.65$ & 0.08 & 0.04 & $F_{2,81}^{2,01}=5.13$ & $<0.001$ & 0.17 \\
\hline Foliar cardenolide & $F_{2,78}=15.54$ & $<0.001$ & 0.22 & $F_{2,78}=0.98$ & 0.38 & 0.01 & $F_{2,78}=7.67$ & $<0.001$ & 0.22 \\
\hline
\end{tabular}

Numbers represent $F$-values, $P$-values and standard $\eta^{2}$ from two-way ANova.

occurred in plants from soils with low $\mathrm{N}$ availability (treatment of $\left.0 \mathrm{~g} \mathrm{~m}^{-2}\right)$, and the lowest concentration $\left(1.90 \pm 0.16 \mathrm{mg} \mathrm{g}^{-1}\right)$ occurred in plants from soils with intermediate $\mathrm{N}$ availability (treatment of $4 \mathrm{~g} \mathrm{~m}^{-2}$ ) (Fig. 1c). Although P fertilisation did not have any significant independent effects on foliar N, P or cardenolide concentrations (in either two-way or one-way ANOVA), there were significant interactive effects of $\mathrm{N}$ and $\mathrm{P}$ fertilisation on all three foliar traits (Table 1). Specifically, when $\mathrm{N}$ availability was low or intermediate, $\mathrm{P}$ fertilisation decreased foliar $\mathrm{N}$ concentration; under high $\mathrm{N}$ concentrations, $\mathrm{P}$ fertilisation increased foliar N concentration (Fig. 1a). Similarly, $\mathrm{P}$ fertilisation $\left(0.4\right.$ and $\left.0.8 \mathrm{~g} \mathrm{~m}^{-2}\right)$ increased foliar $\mathrm{P}$ concentration only under intermediate and high $\mathrm{N}\left(8 \mathrm{~g} \mathrm{~m}^{-2}\right)$ fertilisation levels (Fig. 1b). Finally, under high $\mathrm{N}$ fertilisation, $\mathrm{P}$ fertilisation increased foliar cardenolide concentration, although it decreased cardenolide concentration when $\mathrm{N}$ availability was low or intermediate (Fig. 1c).

Total consumption of plant material by D. plexippus declined with foliar cardenolide concentration (Fig. 2a; $F_{1,65}=7.14$, $\left.P=0.009, \mathrm{R}^{2}=0.10\right)$. In addition, consumption was affected by $\mathrm{N}$ fertilisation (Table 2; $F_{2,61}=11.48, P<0.001$ ) such that total foliar consumption by caterpillars was greatest when $\mathrm{N}$ availability was intermediate (Fig. 2b). On average, total consumption values were $30.2 \%$ and $29.9 \%$ lower, respectively, when caterpillars fed on plants from low and high $\mathrm{N}$ availability, compared with plants from soils with medium $\mathrm{N}$ availability. However, total consumption of cardenolide was unaffected by $\mathrm{N}$ fertilisation (Table $2 ; F_{2,58}=1.05, P=0.36$ ), presumably because cardenolide concentrations were lowest under intermediate $\mathrm{N}$ availability (Fig. 1c), whereas foliar consumption levels were highest (Fig. 2b).

Caterpillar growth rate was reduced by $\mathrm{N}$ fertilisation (Table 2, Fig. 2 c; $\left.F_{2,61}=13.05, P<0.001\right)$. Compared with caterpillars fed on plants with low soil $\mathrm{N}$ availability, caterpillars exhibited $28.9 \%$ and $59.7 \%$ reductions in growth rate, respectively, when they fed on plants from soils of medium $\mathrm{N}$ and high $\mathrm{N}$ availability. $\mathrm{P}$ fertilisation also reduced caterpillar growth rate (Table 2, Fig. 2d; $F_{2,61}=3.82, P=0.03$ ), although the effects were not as strong as those of $\mathrm{N}$ fertilisation. Specifically, compared with caterpillars fed on plants with low soil $\mathrm{P}$ availability, caterpillars exhibited $14.3 \%$ and $31.4 \%$ reductions in growth rate when they fed on plants from soils of medium $\mathrm{P}$ and high $\mathrm{P}$ availability, respectively. There was a strong positive correlation between caterpillar growth rate and sequestration efficiency of cardenolide (Fig. 2e; $F_{1,61}=141.93, P<0.001$, $\mathrm{R}^{2}=0.73$ ).

Sequestration efficiency was negatively correlated with foliar cardenolide concentration (Fig. 2f; $F_{1,61}=11.50, P=0.001$, $\mathrm{R}^{2}=0.16$ ). Moreover, $\mathrm{N}$ fertilisation reduced sequestration efficiency of caterpillars (see Table 2 for full model, Fig. 3a; one-way ANOvA: $\left.F_{2,60}=4.87, P=0.01\right)$. On average, sequestration efficiency was $12.8 \%$ and $34.5 \%$ lower when caterpillars fed on plants from soils of medium and high $\mathrm{N}$ availability, respectively. High $\mathrm{P}$ fertilisation level, but not intermediate $\mathrm{P}$ level, also reduced sequestration efficiency (Fig. 3b; one-way ANOVA: $\left.\mathrm{F}_{2,60}=4.72, P=0.01\right)$. The marginally non-significant
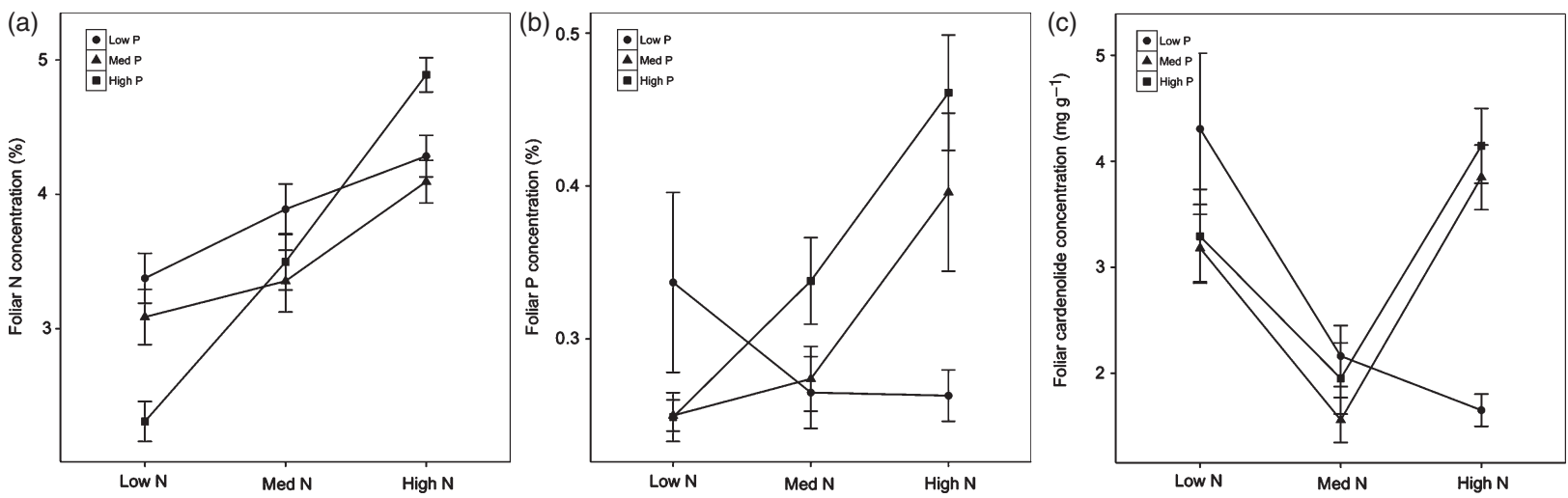

Fig. 1. $(\mathrm{a}-\mathrm{c})$ Effects of nitrogen $(\mathrm{N})$ and phosphorus $(\mathrm{P})$ fertilisation on foliar $\mathrm{N}, \mathrm{P}$ and cardenolide concentrations of Asclepias curassavica. Points represent the means of 10 samples and bars represent standard errors. Low, med and high $\mathrm{N}$ represent $\mathrm{N}$ fertilisation levels of 0,4 and $8 \mathrm{~g} \mathrm{~m}^{-2}$, and low, med and high $\mathrm{P}$ represent $\mathrm{P}$ fertilisation levels of $0,0.4$ and $0.8 \mathrm{~g} \mathrm{~m}^{-2}$. 
(a)

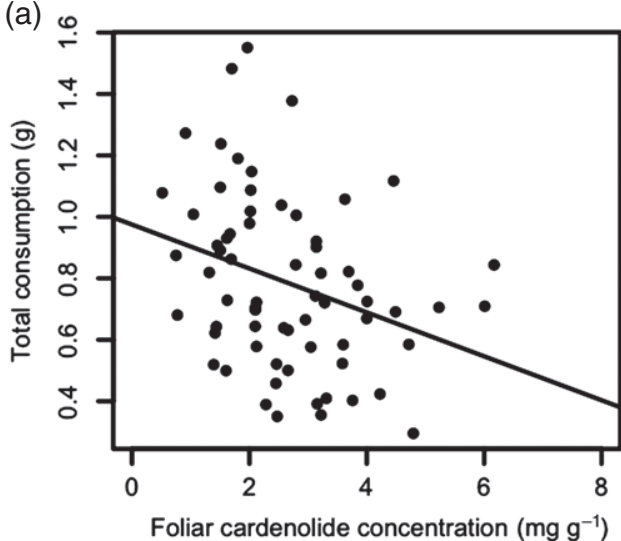

(c)
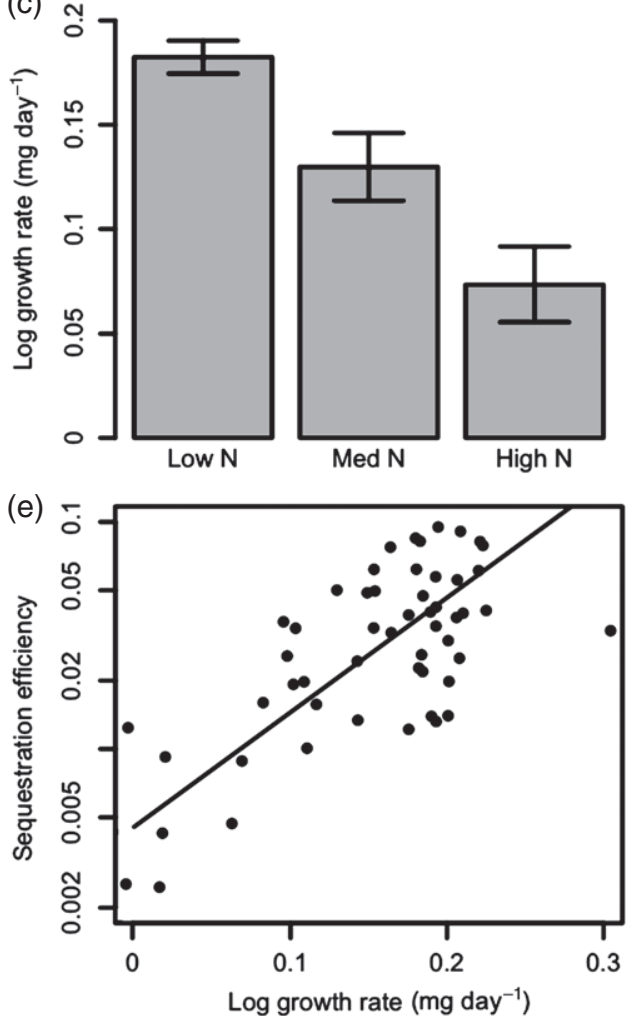

(b)

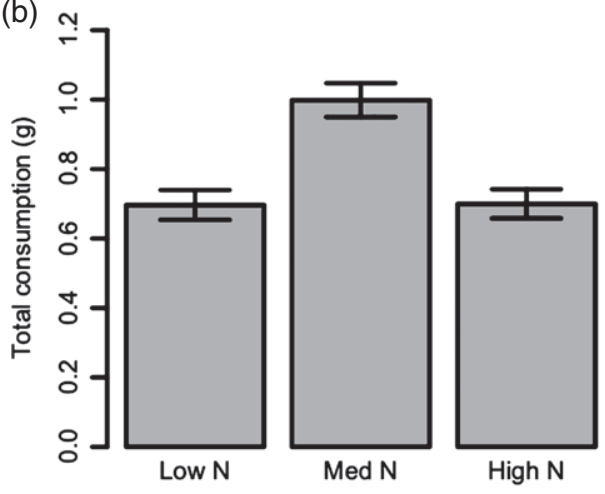

(d)

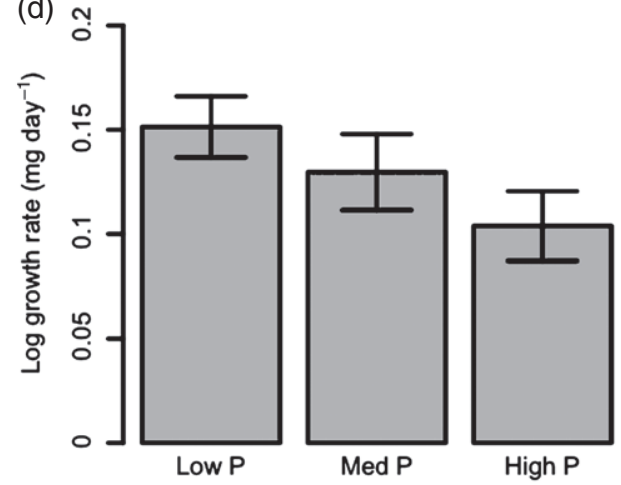

(f)

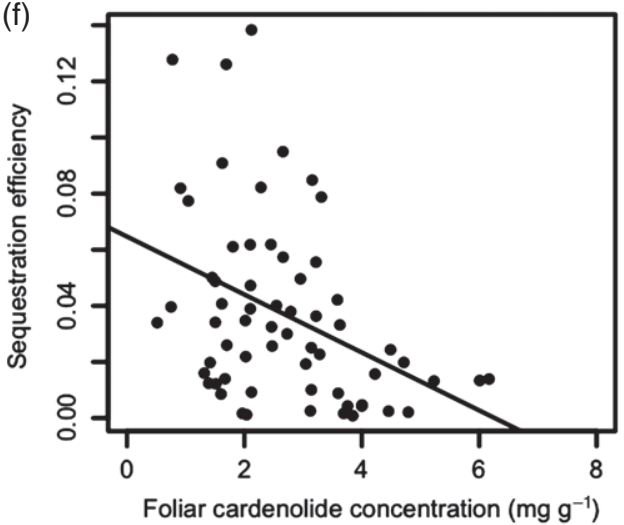

Fig. 2. (a) Relationship between foliar cardenolide concentration and total foliar consumption. (b, c) Effects of nitrogen (N) fertilisation on total foliar consumption (b) and larval growth rate (c). (d) Effects of phosphorus (P) fertilisation on growth rate of Danaus plexippus. Columns are the means of 22-30 samples and bars represent standard errors. (e) Illustrates the positive relationship between caterpillar growth rate and sequestration efficiency and (f) illustrates the negative relationship between foliar cardenolide concentration and sequestration efficiency. Low, med and high $\mathrm{N}$ represent $\mathrm{N}$ fertilisation levels of 0,4 and $8 \mathrm{~g} \mathrm{~m}^{-2}$, and low, med and high P represent P fertilisation levels of $0,0.4$ and $0.8 \mathrm{~g} \mathrm{~m}^{-2}$, respectively.

interaction between $\mathrm{N}$ and $\mathrm{P}$ fertilisation $(\mathrm{p}=0.053$, Table 2) suggested that there were consistent negative effects of $\mathrm{N}$ fertilisation on sequestration efficiency when $\mathrm{P}$ fertilisation levels were intermediate or high. However, when $\mathrm{P}$ fertilisation was low, intermediate, but not high, $\mathrm{N}$ fertilisation reduced sequestration efficiency $(0.05 \pm 0.01,0.03 \pm 0.003,0.05 \pm 0.01$ for low, medium and high $\mathrm{N}$ levels, respectively). Because the total amount of cardenolide consumed by caterpillars was unaffected by fertilisation (see earlier), the effects of $\mathrm{N}$ and $\mathrm{P}$ fertilisation on total cardenolide contents of $D$. plexippus were similar to their effects on sequestration efficiency (Table 2, data not shown). $\mathrm{N}$ fertilisation increased cardenolide concentration in frass (Table 2, Fig. 3c; $F_{2,58}=10.22, P<0.001$ ), consistent with the lower efficiency of cardenolide sequestration under $\mathrm{N}$ fertilisation (Fig. 3a). Frass cardenolide concentrations increased 1.7and 6.4-fold under medium and high $\mathrm{N}$ addition, respectively. Similarly, under high $\mathrm{P}$ fertilisation levels, frass cardenolide concentrations were greater than those under low or medium 
Table 2. Effects of nitrogen $(\mathrm{N})$ and phosphorus $(\mathrm{P})$ fertilisation, and their interactions, on caterpillar growth, foliar consumption, cardenolide excretion and sequestration of cardenolide by Danaus plexippus.

\begin{tabular}{|c|c|c|c|c|c|c|c|c|c|}
\hline & \multicolumn{3}{|l|}{ Soil N } & \multicolumn{3}{|l|}{ Soil P } & \multicolumn{3}{|l|}{ Soil $\mathrm{N} \times \mathrm{P}$} \\
\hline & $F$ & $P$ & $\eta^{2}$ & $F$ & $P$ & $\eta^{2}$ & $F$ & $P$ & $\eta^{2}$ \\
\hline Total consumption & $F_{2,61}=11.48$ & $<0.001$ & 0.25 & $F_{2,61}=1.90$ & 0.16 & 0.04 & $F_{2,61}=0.57$ & 0.69 & 0.03 \\
\hline Consumption of cardenolide & $F_{2,58}=1.05$ & 0.36 & 0.03 & $F_{2,58}^{2,01}=1.59$ & 0.21 & 0.04 & $F_{2,58}^{2,01}=2.33$ & 0.07 & 0.13 \\
\hline Growth rate & $F_{2,61}=13.05$ & $<0.001$ & 0.25 & $F_{2,61}^{2,50}=3.82$ & 0.03 & 0.07 & $F_{2,61}^{2,00}=2.04$ & 0.10 & 0.08 \\
\hline Sequestration efficiency & $F_{2,54}=6.51$ & 0.003 & 0.14 & $F_{2,54}^{2,61}=8.15$ & $<0.001$ & 0.17 & $F_{2,54}^{2,61}=1.88$ & 0.05 & 0.11 \\
\hline Cardenolide concentration in frass & $\mathrm{F}_{2,58}=10.22$ & $<0.001$ & 0.23 & $F_{2,58}^{2, j 4}=2.63$ & 0.08 & 0.06 & $F_{2.58}^{2, J 4}=2.20$ & 0.10 & 0.07 \\
\hline Total cardenolide content & $F_{2,60}=7.32$ & 0.001 & 0.16 & $F_{2,60}^{2,00}=5.83$ & 0.005 & 0.13 & $F_{2,60}=1.23$ & 0.31 & 0.05 \\
\hline Cardenolide concentration & $F_{2,61}^{2,00}=0.34$ & 0.71 & 0.01 & $F_{2,61}^{2,00}=0.29$ & 0.75 & 0.01 & $F_{2,61}^{2,00}=0.80$ & 0.53 & 0.05 \\
\hline
\end{tabular}

Numbers represent $F$-values, $P$-values and standard $\eta^{2}$ from two-way ANOVA.

$\mathrm{P}$ addition, although the effect was marginally non-significant (Table 2, Fig. 3d; $F_{2,58}=2.63, P=0.08$ ). There were no effects of $\mathrm{N}, \mathrm{P}$, cardenolide or any of their interactions on cardenolide concentrations in D. plexippus (Table 2, Fig. 3e,f).

Effects of soil nutrient availability on cardenolide composition in A. curassavica and D. plexippus

The availabilities of $\mathrm{N}$ and $\mathrm{P}$ in soil interact to influence the composition of cardenolides in the tissues of both $A$. curassavica $\left(F_{4,78}=4.35, P<0.001\right)$ and $D$. plexippus $\left(F_{4,61}=6.60\right.$, $P<0.001$ ) (Table 3, Fig. 4). NMDS plots illustrated that when soil $\mathrm{N}$ availability was low or intermediate, the compositions of foliar cardenolides across soil $\mathrm{P}$ treatments were relatively clustered; however, when soil $\mathrm{N}$ availability was high, cardenolide composition became more scattered across soil P. Interestingly, effects of soil $\mathrm{N}$ availability on cardenolide composition in D. plexippus were different from their effects on cardenolide composition in A. curassavica (Fig. 4). Specifically, cardenolide composition in D. plexippus was more clustered when the caterpillars fed on plants with high soil $\mathrm{N}$ availability.

\section{Discussion}

These results illustrate that soil nutrient availability influences both total concentration (Fig. 1c) and the composition (Fig. 4) of cardenolides in the foliage of A. curassavica. Fertilisation has been shown to reduce cardenolide concentration in milkweeds (Agrawal et al., 2012), and we also observed such decreases under medium fertilisation levels. However, under high $\mathrm{N}$ and $\mathrm{P}$ fertilisation levels, cardenolide concentrations were higher than those under medium fertilisation levels. Although the exact mechanism is not clear, our higher levels of fertilisation, while within the range observed from anthropogenic nutrient deposition, may have induced stress in the plants. In response to changes in foliar cardenolide concentrations, monarch caterpillars appear able to regulate the cardenolide concentrations of their tissues so that they do not vary with soil nutrient availability (Fig. 3e,f). In marked contrast, the composition of cardenolides in monarch caterpillars varies substantially with soil nutrient availability (Fig. 4), with soil $\mathrm{N}$ and $\mathrm{P}$ combining to explain a total of $56 \%$ of the variance in caterpillar cardenolide composition (Table 3). Because cardenolide composition influences the susceptibility of monarchs to their parasites (Sternberg et al., 2012), soil nutrient levels, including those imposed by anthropogenic $\mathrm{N}$ deposition, may influence monarch-enemy interactions.

Previous studies have illustrated strong links among soil nutrient availability, the concentration and composition of foliar PSMs, and subsequent sequestration by insect herbivores. For example, $\mathrm{N}$ fertilisation reduces the production of aucubin (an iridoid glycoside) in ribwort plantain (Plantago lanceolata), which subsequently leads to lower levels of aucubin sequestration by common buckeye caterpillars, Junonia coenia (Prudic et al., 2005). By contrast, $\mathrm{N}$ enrichment does not affect antirrhinoside contents in the plant Linaria dalmatica or the herbivore Calophasia lunula, but antirrhinoside concentrations are lower in the herbivore after $\mathrm{N}$ enrichment because of their higher biomass (Jamieson \& Bowers, 2012). Our study adds to this growing body of work, and illustrates that $\mathrm{N}$ deposition may influence the sequestration of PSMs through combined effects on consumption, sequestration efficiency and excretion.

Sequestration efficiency is known to depend on environmental and genetic factors (Camara, 1997) and to vary with other properties of the diet. For example, when $D$. plexippus larvae feed on milkweed species with low cardenolide concentrations, sequestration efficiency is relatively constant across the lower ranges of cardenolide concentrations. However, when feeding on milkweeds with high cardenolide concentrations, sequestration efficiency declines as foliar cardenolide concentrations increase (Lynch \& Martin, 1993), consistent with our results. This may be achieved through two related mechanisms illustrated here. First, monarchs reduce the total amount of foliage that they consume as foliar cardenolide concentrations increase (Fig. 2a). Secondly, they decrease cardenolide sequestration efficiency as foliar cardenolide concentrations increase (Fig. 2f). The net result is that cardenolide concentrations in caterpillars are positively correlated with those in the foliage of low-cardenolide plants, but unrelated to foliar concentrations in the foliage of high-cardenolide plants (Lynch \& Martin, 1993).

Sequestration is an active process, accomplished by transport proteins in the hemolymph (Frick \& Wink, 1995; Hartmann, 2004). Therefore, insects may control the uptake of different defence compounds as well as their total amounts. For 
(a)

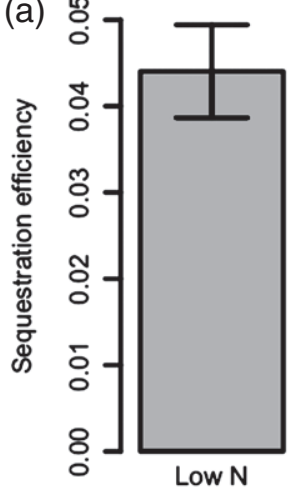

(c)

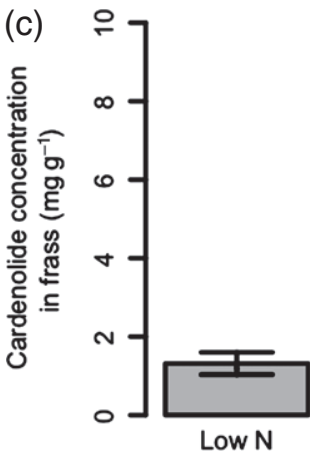

(e)

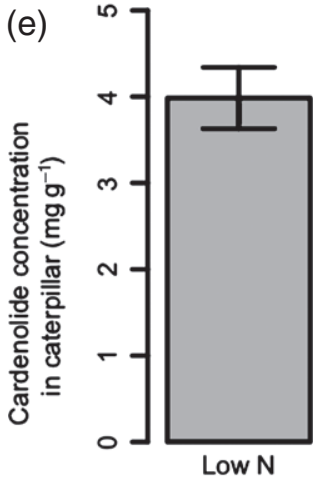

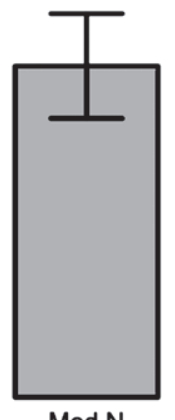

Med N

Med N

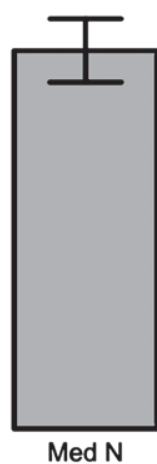

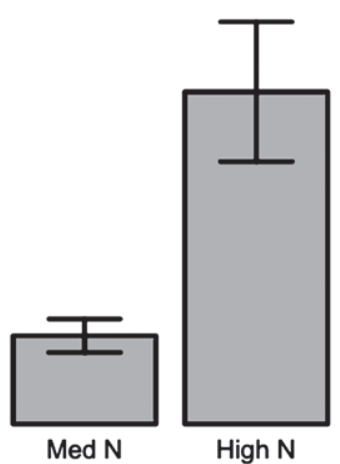
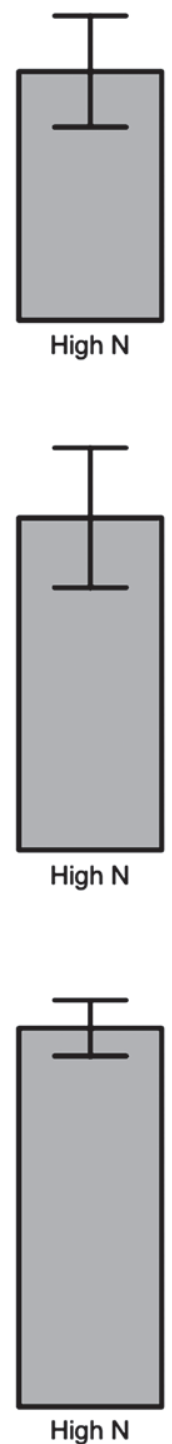

(b)

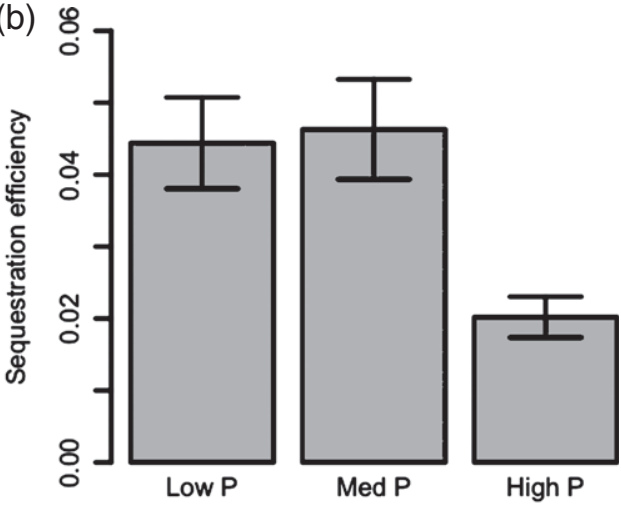

(d)
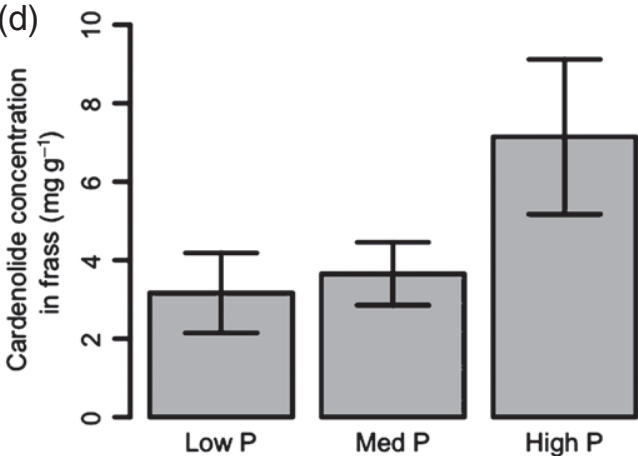

(f)

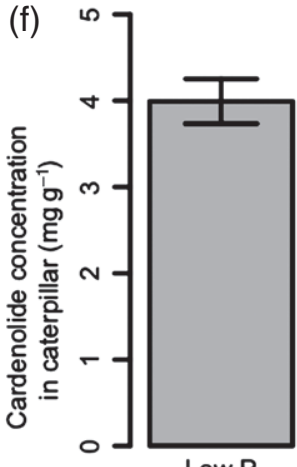

Low P

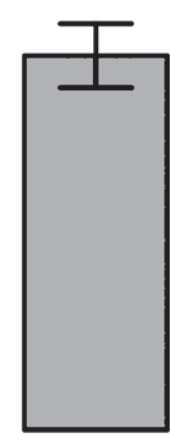

Med P

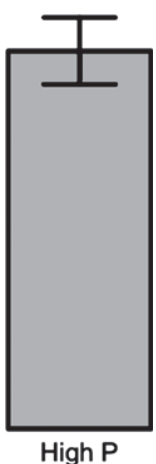

Fig. 3. Effects of nitrogen $(\mathrm{N})$ (a, c, e) and phosphorus (P) fertilisation (b, d, f) on sequestration efficiency (a and b, respectively), cardenolide concentration in frass ( $\mathrm{c}$ and $\mathrm{d}$, respectively) and cardenolide concentration (e and $\mathrm{f}$, respectively) in Danaus plexippus. Columns are the means of 22-30 samples and bars represent standard errors.

example, flea beetles in the genus Longitarsus selectively store simple pyrrolizidine alkaloid (PA) monoesters as opposed to more complex compounds (Dobler et al., 2000). Similarly, the catalpa sphinx caterpillar Ceratomia catalpae selectively stores catalpol instead of catalposide from its host plant Catalpa bignonioides (Bowers, 2003). Such selective sequestration may have evolved to avoid autotoxicity of the sequestered chemicals. For example, the beetle Oreina cacaliae, which sequesters pyrrolizidine alkaloids, absorbs and stores non-toxic $\mathrm{N}$-oxide compounds, while pro-toxic free base pyrrolizidine alkaloids are detoxified by glucosylation (Hartmann et al.,
1999). Similarly, in our system, D. plexippus can selectively sequester cardenolides with intermediate polarity as opposed to low-polarity cardenolides (Malcolm \& Brower, 1989), presumably because lipophilic cardenolides are more toxic to the insect (Fordyce \& Malcolm, 2000; Sternberg et al., 2012). In the current experiment, to measure the overall polarity of cardenolide compounds, we calculated the non-polarity index following Rasmann and Agrawal (2011). We also observed that, on average, the non-polarity index of caterpillars $(0.51 \pm 0.01)$ was lower than that of the plants $(0.69 \pm 0.01)$, suggesting that caterpillars selectively sequestered cardenolides with intermediate 
Table 3. PERMANOva results of the effects of soil $\mathrm{N}$ and $\mathrm{P}$ availability, and their interactions, on cardenolide composition in Asclepias curassavica and Danaus plexippus.

\begin{tabular}{|c|c|c|c|c|c|c|}
\hline & \multicolumn{3}{|c|}{ A. curassavica } & \multicolumn{3}{|l|}{ D. plexippus } \\
\hline & $F$ & $P$ & $R^{2}$ & $F$ & $P$ & $R^{2}$ \\
\hline Soil N & $F_{2,78}=3.69$ & $<0.001$ & 0.06 & $F_{2,61}=19.38$ & $<0.001$ & 0.28 \\
\hline Soil P & $F_{2,78}=7.11$ & $<0.001$ & 0.12 & $F_{2,61}=6.34$ & $<0.001$ & 0.09 \\
\hline Soil $\mathrm{N} \times \mathrm{P}$ & $F_{4,78}=4.35$ & $<0.001$ & 0.15 & $F_{4,61}^{2,01}=6.60$ & $<0.001$ & 0.19 \\
\hline
\end{tabular}

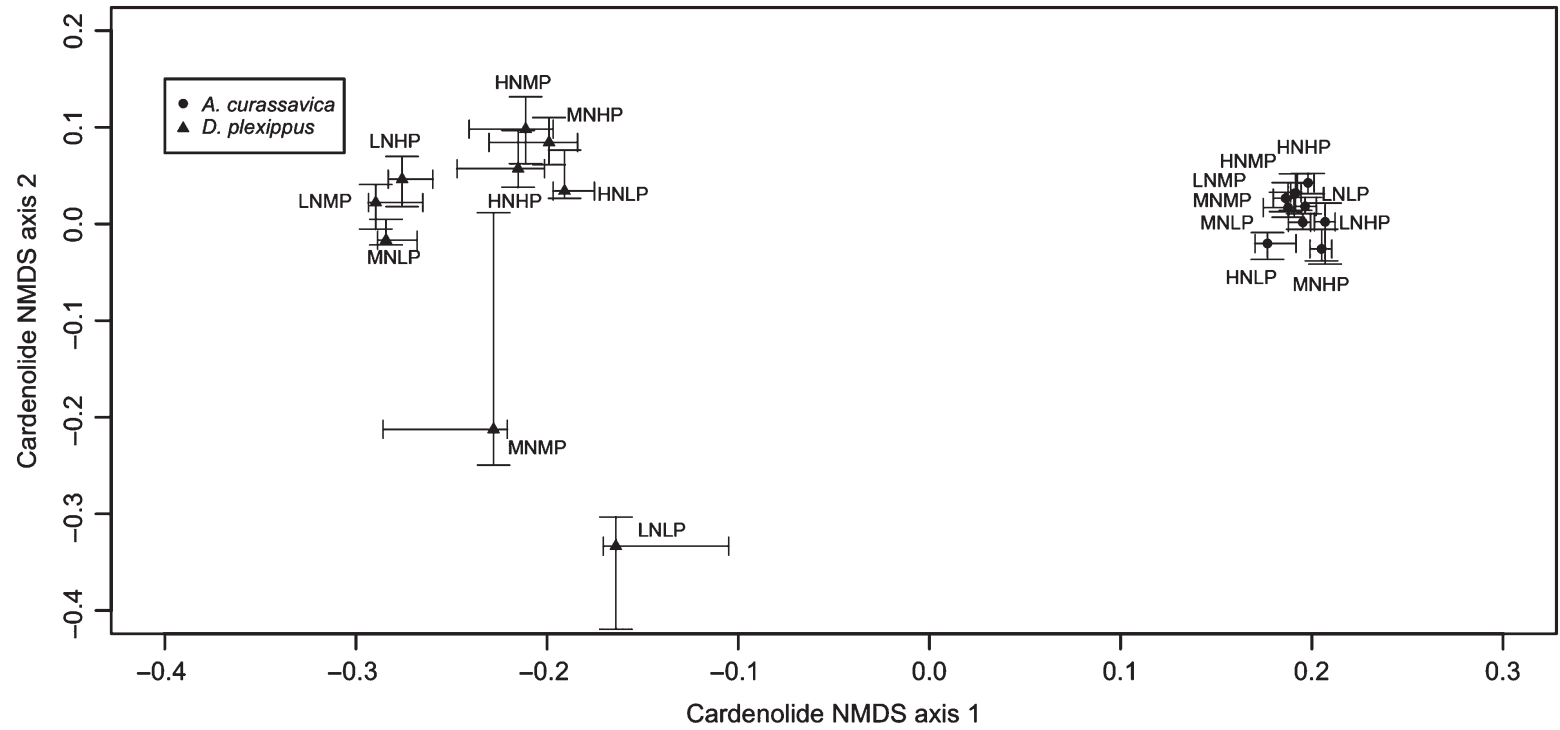

Fig. 4. Effects of soil nitrogen $(\mathrm{N})$ and phosphorus $(\mathrm{P})$ availability on Asclepias curassavica and Danaus plexippus cardenolide composition. Points and error bars represent the median and interquartile range (25-75\%), respectively, of non-metric multidimensional scaling (NMDS) scores for plants and herbivores by each treatment. L, M and H represent 'low', 'medium', and 'high' respectively (i.e. HNMP refers to high N, medium P). Low, med and high $\mathrm{N}$ represent $\mathrm{N}$ fertilisation levels of 0,4 and $8 \mathrm{~g} \mathrm{~m}^{-2}$, and low, med and high $\mathrm{P}$ represent $\mathrm{P}$ fertilisation levels of $0,0.4$ and $0.8 \mathrm{~g} \mathrm{~m}^{-2}$.

polarity. Previously, we have found that the toxicity of cardenolides to $D$. plexippus increases under high foliar $\mathrm{N}$ concentration (Tao et al., 2014). The reduced sequestration efficiency that we observed here under high $\mathrm{N}$ availability (Fig. 3a) may serve as an additional example of regulation of sequestration to avoid autotoxicity.

Alternatively, the fact that $\mathrm{N}$ fertilisation reduced sequestration efficiency could be explained by lower growth rates under high $\mathrm{N}$ treatment levels. The metabolic stress of dealing with a high $\mathrm{N}$ diet (Boersma \& Elser, 2006; Zehnder \& Hunter, 2009), which is known to impose a fitness cost on monarchs when cardenolides are high (Tao et al., 2014), may have imposed costs on growth rate that then limited the ability of caterpillars to sequester cardenolides. In some insect species, sequestration is a high cost process (Bowers, 1992) while in other species, sequestration does not incur significant costs (Kearsley \& Whitham, 1992; Camara, 1997). In monarch caterpillars, findings are mixed. While physiological studies suggest that metabolising cardenolides is relatively inexpensive (Erickson, 1973; Vaughan \& Jungreis, 1977), ecological studies report that cardenolide sequestration correlates negatively with body mass (Cohen, 1985) and migration distance (Brower et al., 1972; Brower \& Glazier, 1975). Here, because cardenolide concentrations in caterpillars were strikingly similar across nutrient treatments (Fig. 3e,f), we favour the notion that reduced caterpillar growth rates represent a cost of managing consumption (Fig. 2a) and sequestration efficiency (Fig. 2f) to maintain constant cardenolide levels in body tissues.

During sequestration, PSMs can be directly absorbed, metabolised or excreted (Nishida, 2002; Hartmann, 2004; Opitz $\&$ Müller, 2009). The reduction in sequestration efficiency that we observed here under high nutrient availability may result, at least in part, from increases in the excretion of cardenolides (Fig. 3c,d), perhaps from faster gut passage rates or lower absorption efficiency of the food. Faster gut passage times significantly reduce the mortality rate of gypsy moth Lymatria dispar caused by nuclear polyhedrosis virus (Keating et al., 1990). Similarly, infection rates of monarch caterpillars by Ophryocystis elektroscirrha, a protozoan parasite, may decline as food passage rates increase. Because parasite infection is also related to dietary cardenolides (Lefevre et al., 2010; de Roode et al., 2011), this illustrates an interesting future direction of incorporating cardenolide toxicity, $\mathrm{N}$ deposition and parasite infection in tritrophic studies of plant-insect-parasite interactions under global change. 


\section{Acknowledgements}

This work was supported by an Angeline B. Whittier fellowship and a Barbour fellowship from the University of Michigan to L.T., and NSF DEB-0814340 and NSF DEB-1019746 to M.D.H. Hannah DeRose-Wilson and Mary Cate Cartmill provided great help with plant and insect maintenance. Michael Grant from the Biological Station of UM performed the nutrient analyses. We thank two anonymous reviewers, Beth Pringle, Leslie Decker, Katherine Crocker, Holly Andrews, Hillary Streit, Amanda Meier and N. Omar Bonilla for constructive comments on an earlier draft.

\section{References}

Agrawal, A.A., Petschenka, G., Bingham, R.A., Weber, M.G. \& Rasmann, S. (2012) Toxic cardenolides: chemical ecology and coevolution of specialized plant-herbivore interactions. New Phytologist, 194, $28-45$.

Anderson, M.J. (2001) A new method for non-parametric multivariate analysis of variance. Austral Ecology, 26, 32-46.

Awmack, C.S. \& Leather, S.R. (2002) Host plant quality and fecundity in herbivorous insects. Annual Review of Entomology, 47, 817-844.

Bernays, E. \& Chapman, R. (1987) The evolution of deterrent responses in plant-feeding insects. Perspectives in Chemoreception and Behavior (ed. by R. F. Chapman, E. A. Bernays and J. G. Stoffolano Jr.), pp. 159-173. Springer, New York, New York.

Bobbink, R., Hicks, K., Galloway, J., Spranger, T., Alkemade, R., Ashmore, M. et al. (2010) Global assessment of nitrogen deposition effects on terrestrial plant diversity: a synthesis. Ecological Applications, 20, 30-59.

Boersma, M. \& Elser, J.J. (2006) Too much of a good thing: on stoichiometrically balanced diets and maximal growth. Ecology, 87, 1325-1330.

Bowers, M.D. (1992) The evolution of unpalatability and the cost of chemical defense in insects. Insect Chemical Ecology: An Evoluationary Approach (ed. by B. D. Roitberg and M. B. Isman), pp. 216-244. Chapman and Hall, New York, New York.

Bowers, M.D. (2003) Hostplant suitability and defensive chemistry of the catalpa sphinx, Ceratomia catalpae. Journal of Chemical Ecology, 29, 2359-2367.

Bowers, M.D. \& Collinge, S. (1992) Fate of iridoid glycosides in different life stages of the Buckeye, Junonia coenia (Lepidoptera: Nymphalidae). Journal of Chemical Ecology, 18, 817-831.

Brower, L.P. \& Glazier, S.C. (1975) Localization of heart poisons in the monarch butterfly. Science, 188, 19-25.

Brower, L.P., McEvoy, P.B., Williamson, K.L. \& Flannery, M.A. (1972) Variation in cardiac glycoside content of monarch butterflies from natural populations in eastern North America. Science, 177, 426-429.

Bukovinszky, T., Poelman, E., Gols, R., Prekatsakis, G., Vet, L.M., Harvey, J. et al. (2009) Consequences of constitutive and induced variation in plant nutritional quality for immune defence of a herbivore against parasitism. Oecologia, 160, 299-308.

Burghardt, F., Proksch, P. \& Fiedler, K. (2001) Flavonoid sequestration by the common blue butterfly Polyommatus icarus: quantitative intraspecific variation in relation to larval hostplant, sex and body size. Biochemical Systematics and Ecology, 29, 875-889.

Camara, M. (1997) Physiological mechanisms underlying the costs of chemical defence in Junonia coenia Hubner (Nymphalidae): a gravimetric and quantitative genetic analysis. Evolutionary Ecology, 11, 451-469.
Cohen, J.A. (1985) Differences and similarities in cardenolide contents of queen and monarch butterflies in Florida and their ecological and evolutionary implications. Journal of Chemical Ecology, 11, 85-103.

Cohen, J. (1988) Statistical Power Analysis for the Behavioral Sciences, 2nd edn. Lawrence Eerlbaum Associates, Hillsdale, New Jersey.

Dobler, S., Haberer, W., Witte, L. \& Hartmann, T. (2000) Selective sequestration of pyrrolizidine alkaloids from diverse host plants by Longitarsus flea beetles. Journal of Chemical Ecology, 26, $1281-1298$

Docherty, M., Hurst, D.K., Holopainen, J.K., Whittaker, J.B., Lea, P.J. \& Watt, A.D. (1996) Carbon dioxide-induced changes in beech foliage cause female beech weevil larvae to feed in a compensatory manner. Global Change Biology, 2, 335-341.

Elser, J.J., Fagan, W.F., Denno, R.F., Dobberfuhl, D.R., Folarin, A., Huberty, A. et al. (2000) Nutritional constraints in terrestrial and freshwater food webs. Nature, 408, 578-580.

Erickson, J.M. (1973) The utilization of various Asclepias species by larvae of the monarch butterfly, Danaus plexippus. Psyche, 80, 230-244.

Fenn, M.E., Haeuber, R., Tonnesen, G.S., Baron, J.S., Grossman-Clarke, S., Hope, D. et al. (2003) Nitrogen emissions, deposition, and monitoring in the western United States. Bioscience, 53, 391-403.

Fordyce, J. \& Malcolm, S. (2000) Specialist weevil, Rhyssomatus lineaticollis, does not spatially avoid cardenolide defenses of common milkweed by ovipositing into pith tissue. Journal of Chemical Ecology, 26, 2857-2874.

Frick, C. \& Wink, M. (1995) Uptake and sequestration of ouabain and other cardiac glycosides in Danaus plexippus (Lepidoptera: Danaidae): evidence for a carrier-mediated process. Journal of Chemical Ecology, 21, 557-575.

Galloway, J.N., Dentener, F.J., Capone, D.G., Boyer, E.W., Howarth, R.W., Seitzinger, S.P. et al. (2004) Nitrogen cycles: past, present, and future. Biogeochemistry, 70, 153-226.

Hartmann, T. (2004) Plant-derived secondary metabolites as defensive chemicals in herbivorous insects: a case study in chemical ecology. Planta, 219, 1-4.

Hartmann, T., Theuring, C., Schmidt, J., Rahier, M. \& Pasteels, J.M. (1999) Biochemical strategy of sequestration of pyrrolizidine alkaloids by adults and larvae of chrysomelid leaf beetles. Journal of Insect Physiology, 45, 1085-1095.

Holzinger, F. \& Wink, M. (1996) Mediation of cardiac glycoside insensitivity in the monarch butterfly (Danaus plexippus): role of an amino acid substitution in the ouabain binding site of $\mathrm{Na}+\mathrm{K}+$-ATPase. Journal of Chemical Ecology, 22, 1921-1937.

Jamieson, M.A. \& Bowers, M.D. (2012) Plant-mediated effects of soil nitrogen enrichment on a chemically defended specialist herbivore, Calophasia lunula. Ecological Entomology, 37, 300-308.

Kearsley, M.C. \& Whitham, T. (1992) Guns and butter: a no cost defense against predation for Chrysomela confluens. Oecologia, 92, $556-562$.

Keating, S.T., Hunter, M.D. \& Schultz, J.C. (1990) Leaf phenolic inhibition of gypsy moth nuclear polyhedrosis virus role of polyhedral inclusion body aggregation. Journal of Chemical Ecology, 16, $1445-1457$.

Keinänen, M., Julkunen-Tiitto, R., Mutikainen, P., Walls, M., Ovaska, J. \& Vapaavuori, E. (1999) Trade-offs in phenolic metabolism of silver birch: effects of fertilization, defoliation, and genotype. Ecology, 80, 1970-1986.

Lefevre, T., Oliver, L., Hunter, M.D. \& de Roode, J.C. (2010) Evidence for trans-generational medication in nature. Ecology Letters, 13, $1485-1493$

Lynch, S.P. \& Martin, R.A. (1993) Milkweed host plant utilization and cardenolide sequestration by monarch butterflies in Louisiana and Texas. Biology and Conservation of the Monarch Butterfly (ed. by 
S. B. Malcolm and M. P. Zalucki), pp. 107-123. Natural History Museum of Los Angeles County, Los Angeles, California.

Malcolm, S.B. \& Brower, L.P. (1989) Evolutionary and ecological implications of cardenolide sequestration in the monarch butterfly. Experientia, 45, 284-295.

Malcolm, S., Cockrell, B. \& Brower, L. (1989) Cardenolide fingerprint of monarch butterflies reared on common milkweed, Asclepias syriaca L. Journal of Chemical Ecology, 15, 819-853.

Mattson, W.J. (1980) Herbivory in relation to plant nitrogen-content. Annual Review of Ecology and Systematics, 11, 119-161.

Nishida, R. (2002) Sequestration of defensive substances from plants by Lepidoptera. Annual Review of Entomology, 47, 57-92.

Opitz, S.W. \& Müller, C. (2009) Plant chemistry and insect sequestration. Chemoecology, 19, 117-154.

Prudic, K.L., Oliver, J.C. \& Bowers, M.D. (2005) Soil nutrient effects on oviposition preference, larval performance, and chemical defense of a specialist insect herbivore. Oecologia, 143, 578-587.

Rasmann, S. \& Agrawal, A.A. (2011) Latitudinal patterns in plant defense: evolution of cardenolides, their toxicity and induction following herbivory. Ecology Letters, 14, 476-483.

Reichstein, T., von Euw, J., Parsons, J.A. \& Rothschild, M. (1968) Heart poisons in the monarch butterfly. Science, 161, 861-866.

de Roode, J.C., Rarick, R.M., Mongue, A.J., Gerardo, N.M. \& Hunter, M.D. (2011) Aphids indirectly increase virulence and transmission potential of a monarch butterfly parasite by reducing defensive chemistry of a shared food plant. Ecology Letters, 14, 453-461.

Sternberg, E.D., Lefèvre, T., Li, J., de Castillejo, C.L.F., Li, H., Hunter, M.D. et al. (2012) Food plant derived disease tolerance and resistance in a natural butterfly-plant-parasite interactions. Evolution, 66, 3367-3376.

Tao, L. \& Hunter, M.D. (2012) Does anthropogenic nitrogen deposition induce phosphorus limitation in herbivorous insects? Global Change Biology, 18, 1843-1853.
Tao, L., Berns, A.R. \& Hunter, M.D. (2014) Why does a good thing become too much? Interactions between foliar nutrients and toxins determine performance of an insect herbivore. Functional Ecology, 28, 190-196.

Throop, H.L. \& Lerdau, M.T. (2004) Effects of nitrogen deposition on insect herbivory: implications for community and ecosystem processes. Ecosystems, 7, 109-133.

Vaughan, G.L. \& Jungreis, A.M. (1977) Insensitivity of lepidopteran tissues to ouabain: physiological mechanisms for protection from cardiac glycosides. Journal of Insect Physiology, 23, 585-589.

Vitousek, P.M., Aber, J.D., Howarth, R.W., Likens, G.E., Matson, P.A., Schindler, D.W. et al. (1997) Human alteration of the global nitrogen cycle: sources and consequences. Ecological Applications, 7, 737-750.

Vitousek, P.M., Porder, S., Houlton, B.Z. \& Chadwick, O.A. (2010) Terrestrial phosphorus limitation: mechanisms, implications, and nitrogen-phosphorus interactions. Ecological Applications, 20, $5-15$.

Zalucki, M.P., Malcolm, S.B., Paine, T.D., Hanlon, C.C., Brower, L.P. \& Clarke, A.R. (2001) It's the first bites that count: survival of first-instar monarchs on milkweeds. Austral Ecology, 26, 547-555.

Zehnder, C.B. \& Hunter, M.D. (2007) Interspecific variation within the genus Asclepias in response to herbivory by a phloem-feeding insect herbivore. Journal of Chemical Ecology, 33, 2044-2053.

Zehnder, C.B. \& Hunter, M.D. (2009) More is not necessarily better: the impact of limiting and excessive nutrients on herbivore population growth rates. Ecological Entomology, 34, 535-543.

Accepted 26 September 2014

First published online 18 November 2014 